BMJ Open

Diabetes

Research

\& Care

\title{
Children with type 1 diabetes have elevated high-sensitivity C-reactive protein compared with a control group
}

\author{
Pilar Pérez-Segura, ${ }^{1,2}$ Olaya de Dios, ${ }^{3}$ Leticia Herrero, ${ }^{3}$ Claudia Vales-Villamarín, ${ }^{3}$ \\ Isabel Aragón-Gómez, ${ }^{1}$ Teresa Gavela-Pérez, ${ }^{1,2}$ Carmen Garcés, ${ }^{3}$ \\ Leandro Soriano-Guillén (iD) 1,2
}

To cite: Pérez-Segura $P$, de Dios 0 , Herrero L, et al. Children with type 1 diabetes have elevated high-sensitivity C-reactive protein compared with a control group. BMJ Open Diab Res Care 2020;8:e001424. doi:10.1136/ bmjdrc-2020-001424

\section{- Additional material is} published online only. To view please visit the journal online (http://dx.doi.org/10.1136/ bmjdrc-2020-001424).

Received 31 March 2020 Revised 3 June 2020 Accepted 10 June 2020
Check for updates

(C) Author(s) (or their employer(s)) 2020. Re-use permitted under CC BY-NC. No commercial re-use. See rights and permissions. Published by BMJ.

${ }^{1}$ Pediatrics, Instituto de Investigacion Sanitaria de la Fundacion Jimenez Diaz, Madrid, Spain

${ }^{2}$ Pediatrics, Universidad Autonoma de Madrid Facultad de Medicina, Madrid, Spain ${ }^{3}$ Lipid Research Laboratory, Instituto de Investigacion Sanitaria de la Fundacion Jimenez Diaz, Madrid, Spain

Correspondence to Professor Leandro SorianoGuillén;

leandro.soriano@uam.es

\section{ABSTRACT}

Introduction Our objective was to compare highsensitivity C-reactive protein (hSCRP) levels in children with type 1 diabetes, healthy controls, and children with obesity. Additionally, we aimed to analyze the association between hsCRP levels and glycemic control measured by glycohemoglobin $\mathrm{A}(\mathrm{HbA} 1 \mathrm{C})$ and anthropometric and biochemical variables.

Research design and methods We conducted a nonrandomized descriptive study of children with type 1 diabetes matched for sex and age with a control group and group with obesity. We recorded anthropometric parameters and studied variables related to diabetes, blood pressure, lipid profile, and HbA1c. hsCRP was measured by ELISA.

Results We included 49 children with type 1 diabetes, 46 controls, and 40 children with obesity. hsCRP levels were significantly higher in the group with type 1 diabetes compared with controls and nearly significantly lower than in the group comprising children with obesity. We found no correlation between $\mathrm{hsCRP}$ and $\mathrm{HbA} 1 \mathrm{C}$ and characteristics of type 1 diabetes with the exception of albumin to creatinine ratio. Statistically significant association was found between hsCRP and body mass index (BMI) and waist circumference Z-score.

Conclusions The higher hsCRP levels observed in children with type 1 diabetes compared with a control group with a similar BMI suggest a basal inflammatory state that could increase cardiovascular risk. The main factors related to hSCRP are BMl and waist circumference, so obesity prevention should be a priority when performing follow-up in children with type 1 diabetes.

\section{INTRODUCTION}

Although cardiovascular disease (CVD) has been traditionally linked to type 2 diabetes, it is also the most important cause of morbidity and mortality among patients with type 1 diabetes. ${ }^{1}$ Data from large epidemiologic studies worldwide indicate that the incidence of type 1 diabetes has been increasing by $2 \%-5 \%$ worldwide, ${ }^{2}$ and coronary disease is 2-10 times more prevalent among patients with type 1 diabetes compared with nondiabetic subjects. ${ }^{3}$

\section{Significance of this study}

What is already known about this subject?

- It is known that children with type 1 diabetes are more at risk of developing cardiovascular disease compared with non-diabetic subjects. Furthermore, high-sensitivity C-reactive protein (hSCRP) is a wellknown independent inflammation marker involved in the pathogenesis of atherosclerosis.

\section{What are the new findings?}

- This is one of the first studies to simultaneously analyze hsCRP values in children with type 1 diabetes compared with a control group and children with obesity. Our findings indicate that circulating levels of hsCRP were significantly higher in children diagnosed with type 1 diabetes than in healthy control children. The main factors related to hsCRP are body mass index and waist circumference, but the $\mathrm{HbA} 1 \mathrm{C}$ is not related to hsCRP. In our study the mean age is lower than previous reports and includes patients with shorter duration of diabetes disease, which confers more relevance on a high inflammation grade from earliest stage of disease.

\section{How might these results change the focus of} research or clinical practice?

- It is necessary to investigate the potential relationship with other potential markers of disease control. Considering the existence of an inflammatory state since early childhood, we should monitor inflammatory parameters in type 1 diabetes children that would allow to determine the highest risk patients to prevent the cardiovascular disease in these patients.

Some reports conclude that glycemic control measures obtained using glycosylated hemoglobin Alc (HbAlc) could point to a primary risk factor for atherosclerosis in type 1 diabetes. ${ }^{45}$ However, even though the Diabetes Control and Complications Trial found that higher levels of HbAlc were associated with microvascular and macrovascular complications, hyperglycemia does not fully explain the elevated risk of CVD ${ }^{56}$ Data on the 
relationship between HbA1c and cardiovascular complications are weak, as large clinical trials and epidemiological cohort studies in adults have had conflicting results. In addition, long-term studies in children are lacking. ${ }^{3}$ As a result, the study of additional markers that could play a role in the elevated cardiovascular risk and in the inflammatory process and endothelial dysfunction observed in early childhood merits further investigation. ${ }^{46}$ Moreover, recent studies have demonstrated a relationship between acute hypoglycemia and indexes of systemic inflammation. ${ }^{17}$ These studies suggest that hyperglycemia as well as acute hypoglycemia produces complex vascular effects involved in the activation of proinflammatory mechanisms in type 1 diabetes. ${ }^{13}$

High-sensitivity C-reactive protein (hsCRP) is a wellknown independent inflammation marker involved in the pathogenesis of atherosclerosis. This protein is increased in patients with coronary artery disease. ${ }^{6} 8$ Furthermore, because of its precision, accuracy, and standardization, hsCRP is considered one of the best inflammation markers in clinical practice. ${ }^{9}$

Changes in weight can modify hsCRP concentrations in children with type 1 diabetes, and these changes have important implications for clinical practice. ${ }^{4}$ hsCRP is considered an important link between atherosclerosis, CVD, and insulin resistance. ${ }^{810}$ Several studies have identified higher levels of hsCRP as a risk factor for cardiovascular events in children with obesity, ${ }^{11}$ adults with type 1 and type 2 diabetes, ${ }^{8}{ }^{12-14}$ and for the progression of diabetes complications. ${ }^{15} 16$

Despite this evidence, hsCRP has been poorly studied in children with type 1 diabetes. In addition, most studies in adults have included patients with potentially confounding factors such as hypertension, dyslipidemia, obesity, smoking, and diabetes complications, and as a result the extent to which hsCRP is associated with CVD risk factors in children and adolescents has yet to be elucidated. $^{18}$

Taking into account the scarce data available on hsCRP in the pediatric population with type 1 diabetes, our main objective in this study is to compare hsCRP levels in children with type 1 diabetes against a control group of healthy children and another group made up of children with obesity. In designing this study, we hypothesized that HbAlc, as marker of metabolic control of type 1 diabetes, would be related to hsCRP levels.

\section{METHODS}

Type of study

This descriptive study was conducted between January 2018 and November 2019 in the pediatric endocrinology unit of Fundación Jiménez Díaz Hospital, located in Madrid, Spain.

\section{Sample size calculation}

To obtain hsCRP values in patients with type 1 diabetes that were at least twice as high as those of an age and sex-matched control group with an estimated hsCRP value of $0.7 \mathrm{mg} / \mathrm{L}$ (standard deviation score (SDS) of 1.2), ${ }^{11}$ a minimum of 33 subjects in each group is needed to achieve a statistical power $(\beta)$ of $90 \%$ and level of significance $\alpha$ of 0.05 .

\section{Subjects}

A. Group with type 1 diabetes: children between 6 and 18 years of age diagnosed with type 1 diabetes according to the criteria published by the American Diabetes Association, ${ }^{17}$ with confirmed positive pancreatic autoimmunity (ICAS, anti-GAD, and/or anti IA-2). We ruled out patients who presented another chronic disease or complications of diabetes, including renal impairment (no evidence of microalbuminuria at baseline), retinopathy, neuropathy, and cardiac dysfunctions.

B. Control group: healthy children with a body mass index (BMI) of between -1.5 and +1.5 SDS relative to the mean according to reference charts paired with an age and sex-matched group with type 1 diabetes. ${ }^{18}$

C. Group with obesity: children with a BMI of more than 2 SDS over the mean according to reference charts and no other chronic disease, matched with the group with type 1 diabetes mellitus (DM1) by age and sex. ${ }^{18}$

In these three groups, patients with levels of hsCRP $>10$ $\mathrm{mg} / \mathrm{L}$ were removed from analysis since higher levels of hsCRP are considered a marker of an infection or inflammatory process in accordance with American Heart Association guidelines. ${ }^{19}$

\section{Measures}

\section{Clinical and demographic variables}

Age, sex, BMI $\left(\mathrm{kg} / \mathrm{m}^{2}\right.$ and Z-score $),{ }^{18}$ waist circumference ( $\mathrm{cm}$ and Z-score),${ }^{20}$ blood pressure $(\mathrm{mm} \mathrm{Hg}$ and Z-score),${ }^{21}$ Tanner stage. ${ }^{22} 23$

\section{Specific clinical and demographic variables per group}

Group with type 1 diabetes: age at diabetes diagnosis, presence of ketoacidosis at onset, duration of diabetes, insulin regimen (multiple doses or continuous subcutaneous insulin infusion), total daily insulin requirement, urine albumin to creatinine ratio (ACR), and change in HbA1c over the previous year.

\section{Biochemical data}

Blood samples were obtained by venipuncture in the morning on hospital premises after a 12 hours' fasting period. Samples were kept on ice and sent to the laboratory for analysis. Once centrifuged, fractions were separated and frozen at $-70^{\circ} \mathrm{C}$ for future analyses.

Capillary whole blood via finger-prick was collected to measure HbAlc using monoclonal antibody agglutination reaction, DCA Vantage.

ACR was determined in second morning urine sample.

Serum hsCRP was measured with commercial ELISA from Aviscera Bioscience (CRP High Sensitivity SK0008002) according to the manufacturer's instructions. The 


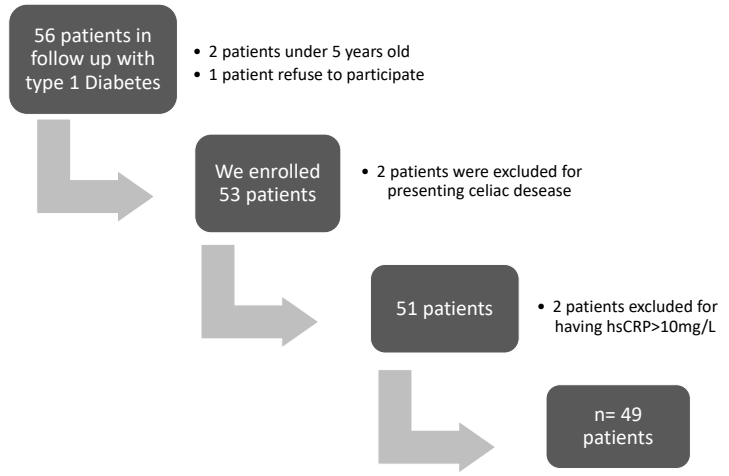

Figure 1 Flow chart of patients with type 1 diabetes. hsCRP, high-sensitivity C-reactive protein.

coefficient of variation intra-assay and interassay was $4.2 \%$ and $9.0 \%$, respectively.

\section{Statistical analyses}

Statistical analyses were performed using SPSS V.21.0 (SPSS). Data are expressed as mean and 95\% CIs. The Kolmogorov-Smirnov test was used to determine whether the variables under study were normally distributed. When possible, variables that were not normally distributed were $\log$ transformed before analysis.

Following this, and in order to evaluate the relationship between hsCRP and the different variables included in the study, a correlation analysis was carried out. Subsequently, a multiple linear regression analysis was performed including hsCRP as the dependent variable.

Analysis of variance was used to compare mean hsCRP values among the three groups and to compare means of biochemical and anthropometric variables by hsCRP risk group according to the classification of the American Cardiovascular Association. ${ }^{19}$

$P$ values $<0.05$ were considered statistically significant. See online supplementary file 1 .

\section{RESULTS}

As seen in figure 1 , the type 1 diabetes group was made up of 49 patients. The demographic and anthropometric data, as well as the biochemical variables of the three groups included in the study, are summarized in table 1.

As we can observe in figure 2, the mean value of hsCRP in the type 1 diabetes group was $2.18 \mathrm{mg} / \mathrm{L}(1.47-2.60)$, significantly higher than the control group $(0.69 \mathrm{mg} / \mathrm{L}$ $(0.48-0.89))$ and nearly significantly lower $(\mathrm{p}=0.064)$ than the group with obesity $(3.37 \mathrm{mg} / \mathrm{L}(2.60-4.21))$.

If we exclude children with type 1 diabetes who presented obesity $(n=2)$, we still observe a significant difference between the group with type 1 diabetes and the control group. Furthermore, in this case, the mean value in type 1 diabetes was 2.06 (1.50-2.63), significantly lower than the one recorded in children with obesity $(\mathrm{p}<0.05)$.

We have designed three groups according to Tanner stage in DM1: Tanner I (3 males/10 females), Tanner
II-IV (12 males/2 females) and Tanner V (13 males/9 females). We have not observed differences in hsCRP between these three groups: $2.17 \mathrm{mg} / \mathrm{L}$ (1.31-3.02), $1.68 \mathrm{mg} / \mathrm{L}(0.32-3.04)$ and $2.26 \mathrm{mg} / \mathrm{L}(1.37-3.16)$, respectively.

We have not observed significant differences of hsCRP between males and females after adjusting by BMI in type 1 diabetes group: $1.74 \mathrm{mg} / \mathrm{L}(1.08-2.39)$ vs $2.81 \mathrm{mg} / \mathrm{L}$ (2.05-3.58).

By dividing children with type 1 diabetes into two groups taking into account the median of duration of diabetes ( $<4.2$ years vs $\geq 4.2$ years), we observed significant differences in hsCRP values: $1.42 \mathrm{mg} / \mathrm{L}$ (0.91-1.93) vs $2.95 \mathrm{mg} / \mathrm{dL}$ (2.07-3.83).

A correlation analysis showed a statistically significant correlation between hsCRP and BMI (Z-score), waist circumference (Z-score), and ACR (table 2). The correlation between hsCRP and ACR remained significant after adjusting for BMI (Z-score) and waist circumference (Z-score). We also observed a nearly significant positive correlation between hsCRP and the duration of diabetes. We have not found a statistically significant relationship with lipid profile even after adjusting by Tanner stage.

Subsequently, a stepwise multivariate linear regression analysis was performed considering hsCRP as a dependent variable and including BMI, waist circumference, and ACR as independent variables. The best model obtained included waist circumference and ACR as independent variables and had an $\mathrm{R}^{2}$ coefficient of $32 \%$, after ruling out collinearity.

Furthermore, we performed the same correlation analysis including only patients with $>4$ years of evolution of diabetes. We only found significant correlation between hsCRP and BMI ( $Z$-score) $(\mathrm{r}=0.58, \mathrm{p}<0.01)$ and waist circumference (Z-score) $(\mathrm{r}=0.64, \mathrm{p}<0.01)$. We have not found significant correlation between hsCRP and ACR.

To further analyze the relationship between hsCRP and characteristics of type 1 diabetes, children with type 1 diabetes were divided into three groups of cardiovascular risk related to hsCRP levels according to the recommendation of the American Heart Association ${ }^{19}$ : low risk (hsCRP $<1 \mathrm{mg} / \mathrm{L}$ ), intermediate risk (hsCRP 1-3 mg/L) and high risk (hsCRP $>3 \mathrm{mg} / \mathrm{L}$ ). We did not observe a significant relationship between them in the duration of diabetes, total doses insulin (UI/ kg/day), HbAlc, average of HbAlc in the last 3, 6 and 12 months, systolic and diastolic blood pressure (Z-score) and lipid profile. We only found a high significant correlation between BMI (Z-score) and waist circumference (Z-score) in the group with higher hsCRP $(>3 \mathrm{mg} / \mathrm{L})(\mathrm{p}<0.01)$.

\section{DISCUSSION}

To our knowledge, this is one of the first studies to simultaneously analyze hsCRP values in children with type 1 diabetes compared with a control group and children with severe obesity. ${ }^{24}$ Our findings indicate that circulating levels of hsCRP were significantly higher in children 
Table 1 Anthropometric and demographic data and biochemical parameters of the control group, children with type 1 diabetes, and children with obesity

\begin{tabular}{|c|c|c|c|c|c|}
\hline & \multirow{2}{*}{$\begin{array}{l}\text { Control group } \\
n=46\end{array}$} & \multirow{2}{*}{$\begin{array}{l}\text { Children with type } 1 \\
\text { diabetes } n=49\end{array}$} & \multirow{2}{*}{$\begin{array}{l}\text { Children with obesity } \\
\mathrm{n}=40\end{array}$} & \multicolumn{2}{|l|}{ ANOVA } \\
\hline & & & & $P$ value & Post hoc \\
\hline Age (years) & $\begin{array}{l}12.46 \\
(11.38-13.54)\end{array}$ & $\begin{array}{l}12.66 \\
(11.57-13.74)\end{array}$ & $\begin{array}{l}13.01 \\
(11.79-14.24)\end{array}$ & \multicolumn{2}{|l|}{ NS } \\
\hline Male/female (\%) & $56 / 44$ & $57 / 43$ & $45 / 55$ & \multicolumn{2}{|l|}{ NS } \\
\hline Tanner stage (n) & $\begin{array}{l}\text { Distribution by age group } \\
<10 \text { years: } 11 \\
\text { ( } 2 \text { males } / 9 \text { females) } \\
10-13 \text { years: } 13 \\
\text { ( } 9 \text { males } / 4 \text { females) } \\
>13 \text { years: } 22 \\
\text { (15 males } / 7 \text { females) }\end{array}$ & $\begin{array}{l}\text { Distribution by Tanner } \\
\text { stage } \\
\text { Tanner I: } 13 \\
\text { ( } 3 \text { males } / 10 \text { females) } \\
\text { Tanner II: } 9 \\
\text { ( } 9 \text { females) } \\
\text { Tanner III: } 1 \\
\text { (1 female) } \\
\text { Tanner IV: } 4 \\
\text { ( } 4 \text { males) } \\
\text { Tanner V: } 22 \\
\text { (13 males } / 9 \text { females) }\end{array}$ & $\begin{array}{l}\text { Distribution by Tanner } \\
\text { stage } \\
\text { Tanner I: } 11 \\
\text { ( } 8 \text { males/3 females) } \\
\text { Tanner II: } 9 \\
\text { ( } 6 \text { males/3 females) } \\
\text { Tanner III: } 2 \\
\text { (1 male/1 female) } \\
\text { Tanner IV: } 4 \\
\text { ( } 1 \text { male/3 females) } \\
\text { Tanner V: } 14 \\
\text { ( } 3 \text { males/11 females) }\end{array}$ & \multicolumn{2}{|c|}{$\begin{array}{l}\text { NS (between children with } \\
\text { type } 1 \text { diabetes and with } \\
\text { obesity) }\end{array}$} \\
\hline BMI (Z-score) & $\begin{array}{l}-0.25 \\
(-0.42 /-0.09)\end{array}$ & $\begin{array}{l}0.05 \\
(-0.27 \text { to } 0.36)\end{array}$ & $\begin{array}{l}4.87 \\
(4.44-5.35)\end{array}$ & $<0.001$ & $\begin{array}{l}1-3^{\star \star \star} \\
2-3^{\star \star \star}\end{array}$ \\
\hline $\begin{array}{l}\text { Waist circumference } \\
\text { (Z-score) }\end{array}$ & $\begin{array}{l}0.29 \\
(0.08-0.61)\end{array}$ & $\begin{array}{l}0.44 \\
(0.05-0.83)\end{array}$ & $\begin{array}{l}5.99 \\
(5.32-6.81)\end{array}$ & $<0.001$ & $\begin{array}{l}1-3^{\star \star \star} \\
2-3^{\star \star \star}\end{array}$ \\
\hline $\begin{array}{l}\text { Cholesterol } \\
(\mathrm{mg} / \mathrm{dL})\end{array}$ & $\begin{array}{l}158.5 \\
(152.58-164.51)\end{array}$ & $\begin{array}{l}160.1 \\
(154.02-166.25)\end{array}$ & $\begin{array}{l}148.7 \\
(139.65-157.80)\end{array}$ & NS & \\
\hline $\begin{array}{l}\text { HDL cholesterol } \\
\text { (mg/dL) }\end{array}$ & $\begin{array}{l}48.1 \\
(44.56-51.67)\end{array}$ & $\begin{array}{l}58.1 \\
(54.80-61.48)\end{array}$ & $\begin{array}{l}43.0 \\
(40.23-45.87)\end{array}$ & $<0.001$ & $\begin{array}{l}1-2^{\star \star \star} \\
2-3^{\star \star \star} \\
1-3^{\star}\end{array}$ \\
\hline $\begin{array}{l}\text { Non-HDL cholesterol } \\
(\mathrm{mg} / \mathrm{dL})\end{array}$ & $\begin{array}{l}110.4 \\
(105.5-115.4)\end{array}$ & $\begin{array}{l}97.8 \\
(89.6-106.1)\end{array}$ & $\begin{array}{l}104.3 \\
(95.8-112.8)\end{array}$ & $<0.05$ & $\begin{array}{l}1-2^{*} \\
2-3^{*}\end{array}$ \\
\hline $\begin{array}{l}\text { LDL cholesterol } \\
\text { (mg/dL) }\end{array}$ & $\begin{array}{l}95.6 \\
(90.59-100.62)\end{array}$ & $\begin{array}{l}89.4 \\
(83.89-95.02)\end{array}$ & $\begin{array}{l}89.2 \\
(80.90-97.45)\end{array}$ & NS & \\
\hline $\begin{array}{l}\text { Triglycerides } \\
(\mathrm{mg} / \mathrm{dL})\end{array}$ & $\begin{array}{l}74.09 \\
(68.60-79.57)\end{array}$ & $\begin{array}{l}61.57 \\
(54.63-71.14)\end{array}$ & $\begin{array}{l}95.28 \\
(81.14-109.41)\end{array}$ & $<0.001$ & $\begin{array}{l}1-2^{\star} \\
1-3^{\star} \\
2-3^{\star \star \star}\end{array}$ \\
\hline
\end{tabular}

${ }^{*} \mathrm{P}<0.05 ;{ }^{* *} \mathrm{p}<0.01 ;{ }^{* \star *} \mathrm{p}<0.001$

ANOVA, analysis of variance; BMI, body mass index; HDL, high-density lipoprotein; LDL, low-density lipoprotein; NS, not significant.

diagnosed with type 1 diabetes than in healthy control children. These data support previous studies that found elevated hsCRP in young subjects with DM1. ${ }^{4625}$

We found a positive correlation between hsCRP values and waist circumference and BMI in children with type

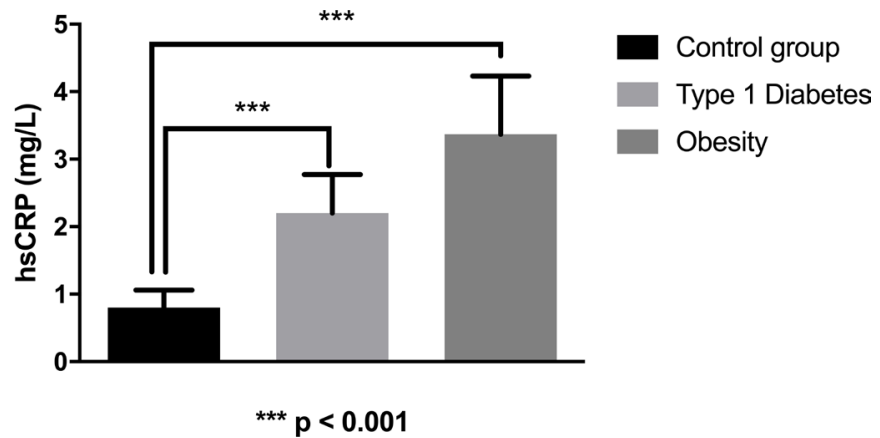

Figure 2 Values of high-sensitivity C-reactive protein (hsCRP) in patients with type 1 diabetes, with obesity, and controls.
1 diabetes. This finding is consistent with the direct relationship between body weight and hsCRP in type 1 diabetes, ${ }^{25}$ and healthy children. ${ }^{11}$ In light of these results, we believe that strict management of nutrition and physical exercise to decrease excess weight in child patients with type 1 diabetes has metabolic benefits (lipid profile, hypertension), ${ }^{26}$ and can decrease the cardiovascular risk of these patients.

By including a group of age, Tanner stage and sexmatched children with obesity to our analysis of diabetic children, we observed that values of hsCRP are lower in children with type 1 diabetes than in children with obesity. In addition, the higher levels of hsCRP observed in type 1 diabetes compared with the control group are not only explained by BMI and waist circumference. In this regard, less than $5 \%$ of children with type 1 diabetes presented obesity. Furthermore, if we exclude children with type 1 diabetes who presented obesity $(n=2)$, we still find a significant difference between values of hsCRP in 
Table 2 Correlation analyses between hsCRP and anthropometric and demographic data and biochemical parameters of children with type 1 diabetes adjusted by Tanner stage

\begin{tabular}{|c|c|c|}
\hline & Type 1 diabetes & $\begin{array}{l}\text { Correlation with } \\
\text { hsCRP }\end{array}$ \\
\hline Age (years) & 12.66 (11.57-13.74) & NS \\
\hline BMI (Z-score) & $0.05(-0.27$ to 0.36$)$ & $r=0.49(p<0.001)$ \\
\hline $\begin{array}{l}\text { Waist circumference } \\
\text { (Z-score) }\end{array}$ & $0.44(0.05-0.83)$ & $r=0.37(p<0.001)$ \\
\hline $\begin{array}{l}\text { Duration of diabetes } \\
\text { (years) }\end{array}$ & 4.91 (3.93-6.01) & $r=0.25(p=0.08)$ \\
\hline TDI (UI/kg/day) & $0.80(0.74-0.86)$ & NS \\
\hline HbA1c baseline & & NS \\
\hline$\%$ & 8.01 (7.56-8.51) & \\
\hline $\mathrm{mmol} / \mathrm{mol}$ & $64(59.1-69.5)$ & \\
\hline $\begin{array}{l}\text { Average of } \mathrm{HbA} 1 \mathrm{c} \\
\text { in the last year of } \\
\text { evolution }\end{array}$ & & NS \\
\hline$\%$ & 8.26 (7.83-8.78) & \\
\hline $\mathrm{mmol} / \mathrm{mol}$ & $66.8(62.8-72.5)$ & \\
\hline ACR & & $r=0.36(p<0.05)$ \\
\hline $\mathrm{mg} / \mathrm{g}$ & $6.93(4.7-9.5)$ & \\
\hline $\mathrm{mg} / \mathrm{mmol}$ & $0.78(0.53-1.07)$ & \\
\hline
\end{tabular}

$\mathrm{ACR}$, albumin to creatinine ratio; BMI, body mass index; $\mathrm{HbA1c}$, glycosylated hemoglobin A1c; hsCRP, high-sensitivity Creactive protein; NS, not significant; TDI, total daily insulin.

children with type 1 diabetes, the control group, and children with obesity. Therefore, there may be an independent basal inflammatory state in type 1 diabetes which warrants further investigation.

In the present study, we have found no significant relationship between levels of hsCRP and HbA1c. This could be explained at least in part by the fact that HbAlc does not appear to be the best marker, as it is influenced by extreme values and does not provide a measure of glycemic variability or hypoglycemia. ${ }^{27}$ Glycemic control could be better evaluated by the combination of HbAlc and data from continuous glucose monitoring like time in range. ${ }^{27} 28$

We also must take into account that more intensive glycemic control is associated with a significant risk of weight gain, ${ }^{34}$ which may influence the levels of hsCRP. One study concluded that there was a significant rise in levels of hsCRP among intensively treated subjects who gained the most weight, thus suggesting a complex relationship that may be influenced by other factors. ${ }^{4}$

We have found a nearly significant relationship between the duration of diabetes and hsCRP in the correlation analysis. Moreover, we have observed a greater increase in hsCRP among children with type 1 diabetes with a longer history of the disease taking into account the median of duration of diabetes. In this regard, one previous study including adolescents described that levels of hsCRP increase with age. ${ }^{29}$ Nevertheless, more studies with higher sample size and with more data on hsCRP over time are necessary to clarify this relationship.

We did not observe a relationship between hsCRP and lipid profile in the type 1 diabetes group. Additionally, no difference in lipid profile was found between the three groups when these were analyzed by cardiovascular risk group. All our patients with type 1 diabetes received nutritional education, and in our facility we monitor the dietary habits of these children during outpatient visits held every 3 months. This could partially explain why our patients have a good lipid profile with no significant relationship with hsCRP. However, in the SEARCH study ${ }^{30}$ it was reported a positive correlation between hsCRP and low-density lipoprotein cholesterol and total cholesterol. Those differences in the results compared with our study could be partially explained by differences in inclusion criteria, sample size, race, BMI, type of diet and hsCRP assay.

We found a significant correlation between values of ACR and hsCRP despite the fact that nephropathy was ruled out. This finding is compatible with other reports that show that microalbuminuria is associated with a state of subclinical inflammation and endothelial dysfunction. ${ }^{29} 3132$ However, how the hsCRP is related to microalbuminuria is not clear. Some studies suggest that this may be the result of inflammation rather than a predictive risk factor for microalbuminuria, ${ }^{29}$ while others hypothesize that hsCRP may play a role in the induction of microalbuminuria, ${ }^{32}$ suggesting that inflammation may deteriorate endothelial dysfunction.

A previous report showed a negative relationship between testosterone and hsCRP in adolescents with obesity. ${ }^{33}$ Although we have not measured sex hormones, the lack of differences of hsCRP related to Tanner stage and gender in the type 1 diabetes group and in children with obesity (data not shown) suggests us that hsCRP levels seem not to be influenced by sexual steroids in our sample.

Our study shows some limitations. First, we used a single measure of hsCRP at baseline, and gathered no data on hsCRP over time. Another limitation is the absence of body composition measurements. Besides, data on the time in range would have been of great interest in patients with continuous glucose monitoring. Finally, we have no data of specific Tanner stage of the control group and we have not measured sex hormones.

\section{CONCLUSIONS}

The higher hsCRP levels observed in children with type 1 diabetes compared with a control group with a similar BMI and lower than children with severe obesity suggest a basal inflammatory state that could increase cardiovascular risk. However, taking into account the present scientific evidence, there are no enough data 
to recommend routine test of hsCRP in the follow-up of children and adolescents with type 1 diabetes. In addition, further longitudinal studies are needed to study the evolution of these individuals until adulthood to evaluate the usefulness of hsCRP as a predictive cardiovascular biomarker.

Notably, in our patients, the main factors related to hsCRP are BMI and waist circumference, so weight control could be essential to the surveillance of patients with type 1 diabetes.

The HbA1c as a relevant indicator of glycemic control is not related to hsCRP. It is therefore necessary to investigate the potential relationship with other potential markers of disease control such as time in range.

\section{Acknowledgements The authors express their gratitude to the study subjects.}

Contributors PPS collected data, performed statistical analyses, and wrote the manuscript. OD, LH, and CVV carried out laboratory work and participated substantially in data analysis. IAG contributed to the collection of data and blood samples. CG supervised laboratory work and critically reviewed the manuscript. TGP and LSG designed the study, supervised data collection, verified data integrity, drafted some sections of the manuscript, made contributions to the interpretation of data, and critically reviewed the manuscript. All authors contributed to the interpretation of data, revised the article critically for important intellectual content, and approved the final version for publication.

Funding This work was supported by Fundación Familia Alonso.

Competing interests None declared.

Patient consent for publication Not required.

Ethics approval Children and parents provided assent and written informed consent, respectively, at the time of enrollment. The study protocol was approved by the Institutional Review Board of the Fundación Jiménez Díaz (code: PIC006-18, approval date: 27 February 2018). This investigation was carried out in adherence to the principles of the Declaration of Helsinki and subsequent reviews, as well as Spanish legislation in force on clinical research in human subjects.

Provenance and peer review Not commissioned; externally peer reviewed.

Data availability statement All data relevant to the study are included in the article or uploaded as supplementary information.

Open access This is an open access article distributed in accordance with the Creative Commons Attribution Non Commercial (CC BY-NC 4.0) license, which permits others to distribute, remix, adapt, build upon this work non-commercially, and license their derivative works on different terms, provided the original work is properly cited, appropriate credit is given, any changes made indicated, and the use is non-commercial. See: http://creativecommons.org/licenses/by-nc/4.0/.

ORCID iD

Leandro Soriano-Guillén http://orcid.org/0000-0003-4268-8870

\section{REFERENCES}

1 de Ferranti SD, de Boer IH, Fonseca V, et al. Type 1 diabetes mellitus and cardiovascular disease: a scientific statement from the American heart association and American diabetes association. Diabetes Care 2014;37:2843-63.

2 Maahs DM, West NA, Lawrence JM, et al. Epidemiology of type 1 diabetes. Endocrinol Metab Clin North Am 2010;39:481-97.

3 Maahs DM, Daniels SR, de Ferranti SD, et al. Cardiovascular disease risk factors in youth with diabetes mellitus: a scientific statement from the American heart association. Circulation 2014;130:1532-58.

4 Schaumberg DA, Glynn RJ, Jenkins AJ, et al. Effect of intensive glycemic control on levels of markers of inflammation in type 1 diabetes mellitus in the diabetes control and complications trial. Circulation 2005;111:2446-53.

5 Nathan DM, DCCT/EDIC Research Group. The diabetes control and complications trial/epidemiology of diabetes interventions and complications study at 30 years: overview. Diabetes Care 2014;37:9-16.
6 Gökșen D, Levent E, Kar S, et al. Serum adiponectin and hsCRP levels and non-invasive radiological methods in the early diagnosis of cardiovascular system complications in children and adolescents with type 1 diabetes mellitus. J Clin Res Pediatr Endocrinol 2013;5:174-81.

7 Gogitidze Joy N, Hedrington MS, Briscoe VJ, et al. Effects of acute hypoglycemia on inflammatory and pro-atherothrombotic biomarkers in individuals with type 1 diabetes and healthy individuals. Diabetes Care 2010;33:1529-35.

8 Karantza MV, Mittelman SD, Dorey F, et al. Relationship of highly sensitive C-reactive protein and lipid levels in adolescents with type 1 diabetes mellitus. Pediatr Diabetes 2008:9:122-6.

9 Roberts WL. Cdc AHA workshop on markers of inflammation and cardiovascular disease: application to clinical and public health practice: laboratory tests available to asses inflammationperformance and standardization: a background paper. Circulation 2004;110.

10 Timar R, Timar B, Degeratu D, et al. Metabolic syndrome, adiponectin and proinflammatory status in patients with type 1 diabetes mellitus. J Int Med Res 2014:42:1131-8.

11 Navarro P, de Dios O, Gavela-Pérez T, et al. High-Sensitivity $\mathrm{C}$-reactive protein and leptin levels related to body mass index changes throughout childhood. J Pediatr 2016;178:178-82.

12 Aburawi EH, AlKaabi J, Zoubeidi T, et al. Subclinical inflammation and endothelial dysfunction in young patients with diabetes: a study from United Arab Emirates. PLoS One 2016;11:e0159808.

13 Balamir I, Ates I, Topcuoglu C, et al. Association of Endocan, Ischemia-Modified albumin, and hsCRP levels with endothelial dysfunction in type 2 diabetes mellitus. Angiology 2018;69:609-16.

14 Sahakyan K, Klein BEK, Lee KE, et al. Inflammatory and endothelial dysfunction markers and proteinuria in persons with type 1 diabetes mellitus. Eur J Endocrinol 2010;162:1101-5.

15 Hansen TK, Forsblom C, Saraheimo M, et al. Association between mannose-binding lectin, high-sensitivity C-reactive protein and the progression of diabetic nephropathy in type 1 diabetes. Diabetologia 2010;53:1517-24.

16 Muni RH, Kohly RP, Lee EQ, et al. Prospective study of inflammatory biomarkers and risk of diabetic retinopathy in the diabetes control and complications trial. JAMA Ophthalmol 2013;131:514-21.

17 American Diabetes Association. Classification and Diagnosis of Diabetes: Standards of Medical Care in Diabetes-2018. Diabetes Care 2018;41:S13-27.

18 Hernández M, Castellet J, Narvaíza JL, et al. Curvas $Y$ tablas de crecimiento IICD (ISBN; 84-7391-177-6). Bilbao: Fundación Faustino Orbegozo, 1988.

19 Ridker PM. Cardiology patient page. C-reactive protein: a simple test to help predict risk of heart attack and stroke. Circulation 2003;108:e81-5.

20 Moreno LA, Fleta J, Mur L, et al. Waist circumference values in Spanish children--gender related differences. Eur J Clin Nutr 1999;53:429-33.

21 National High Blood Pressure Education Program Working Group on High Blood Pressure in Children and Adolescents. The fourth report on the diagnosis, evaluation, and treatment of high blood pressure in children and adolescents. Pediatrics 2004;114:555-76.

22 Marshall WA, Tanner JM. Variations in pattern of pubertal changes in girls. Arch Dis Child 1969;44:291-303.

23 Marshall WA, Tanner JM. Variations in the pattern of pubertal changes in boys. Arch Dis Child 1970;45:13-23.

24 Mangge H, Schauenstein K, Stroedter L, et al. Low grade inflammation in juvenile obesity and type 1 diabetes associated with early signs of atherosclerosis. Exp Clin Endocrinol Diabetes 2004;112:378-82.

25 Prado MM, Carrizo T, Abregú AV, et al. Non-HDL-cholesterol and C-reactive protein in children and adolescents with type 1 diabetes. J Pediatr Endocrinol Metab 2017;30:285-8.

26 Downie ML, Ulrich EH, Noone DG. An update on hypertension in children with type 1 diabetes. Can J Diabetes 2018;42:199-204.

27 American Diabetes Association. 6. Glycemic Targets: Standards of Medical Care in Diabetes-2019. Diabetes Care 2019;42:S61-70.

28 DiMeglio LA, Acerini CL, Codner E, et al. ISPAD clinical practice consensus guidelines 2018: glycemic control targets and glucose monitoring for children, adolescents, and young adults with diabetes. Pediatr Diabetes 2018;19:105-14.

29 Marcovecchio ML, Giannini C, Widmer B, et al. C-Reactive protein in relation to the development of microalbuminuria in type 1 diabetes: the Oxford regional prospective study. Diabetes Care 2008;31:974-6.

30 Snell-Bergeon JK, West NA, Mayer-Davis EJ, et al. Inflammatory markers are increased in youth with type 1 diabetes: the search case-control study. J Clin Endocrinol Metab 2010;95:2868-76. 
31 Yan J-tao, Ye H, Wang D-wen. [The relationship between microalbuminuria and plasma high sensitivity $\mathrm{C}$ reactive protein] Zhonghua Xin Xue Guan Bing Za Zhi 2005;33:534-5.

32 Goud BKM, Nayal B, Devi OS, et al. Comparison of microalbuminuria with hs-CRP and low density lipoprotein levels in nondiabetic, nonhypertensive myocardial infarction patients. $J$ Cardiovasc Dis Res 2012;3:287-9.

33 Mogri M, Dhindsa S, Quattrin T, et al. Testosterone concentrations in young pubertal and post-pubertal obese males. Clin Endocrinol 2013;78:593-9. 